\title{
What is that's going on here? A multidimensional time concept is foundational to framing for decision making in situations of uncertainty
}

\author{
Federica Raia ${ }^{1,2} \cdot$ Lezel Legados $^{1}$ - Irina Silacheva ${ }^{2}$ Jennifer B. Plotkin ${ }^{2}$. \\ Srikanth Krishnan ${ }^{1,2} \cdot$ Mario C. Deng ${ }^{2}$
}

Received: 1 February 2021 / Accepted: 30 March 2021 / Published online: 8 July 2021

(C) The Author(s) 2021

\begin{abstract}
STEM disciplines are the dominant culture in K-12 education. With its study of organs and diseases that afflict patients' bodies, Western evidence-based medicine is seen and understood in the modern cultural paradigm as a science and as the practice in which a subject, the doctor, acts on an object; the patient's body—a dominant culture in the patient's journey. However, with the continually evolving high-technological and medical knowledge, life-saving therapeutic options are life-changing. They can range from changes in the diet, requiring structural and cultural changes in family life, to changes related to the experiences of learning to live tethered to a machine that is partly inside and partly outside one's body or with somebody else's heart. In this article, we show how competing needs to personalize care for the patient as a person forcefully emerge in response to evidence-based medicine's global cultural dominance. We highlight two fundamental issues emerging in decision-making processes: (1) Framing evidence-based knowledge, uncertainties of the course of the disease and options, and (2) working with different, equally important, and often at odds conceptions of time in the care for the Other. Through the longitudinal analysis of moment-to-moment interactions in high-tech medicine encounters of a patient, his family, and the team caring for them, we show how framing and different conceptions of time emerge as issues, are profoundly interconnected, and are addressed by participants to care for a patient confronting existential decisions.
\end{abstract}

Keywords Care $\cdot$ Framing $\cdot$ Multidimensions of time $\cdot$ Professional vision $\cdot$ Shared decision making

Lead Editor: K. Tobin.

This manuscript is part of the special issue Contemplative Inquiry, Wellbeing and Science Education, guest edited by Kenneth Tobin.

Federica Raia

raia@gseis.ucla.edu

Extended author information available on the last page of the article 


\section{Abstract in Italian}

La cultura scientifica ha un ruolo dominante nell'istruzione scolastica negli USA. Con lo studio degli organi e delle malattie che affliggono il corpo dei pazienti, la medicina occidentale, basata sulle prove di efficacia clinica, è vista e intesa nel paradigma culturale moderno sia come scienza sia come attività pratica in cui un soggetto, il medico, agisce sull'oggetto, il corpo del paziente - la medicina è la cultura dominante del percorso che deve intraprendere il paziente.

Tuttavia, con le conoscenze mediche e tecnologiche in continua evoluzione, le moderne opzioni terapeutiche salvavita stanno modificando l'esistenza dei pazienti. Le terapie possono variare dal mutamento della dieta, il che richiede trasformazioni strutturali e culturali all'interno della vita familiare, a cambiamenti connessi alla necessità di imparare a convivere con una macchina che è in parte interna e in parte esterna al proprio corpo o con un cuore o un altro organo estraneo.

In questo articolo mostriamo come le esigenze di personalizzare l'assistenza al paziente in quanto persona emergano con forza in contrapposizione al predominio culturale dominante della medicina basata sulle prove di efficacia clinica. Evidenziamo qui due questioni fondamentali che emergono nei processi decisionali: 1) Inquadrare (framing) la conoscenza basata sulle prove di efficacia clinica, le incertezze del decorso della malattia e delle opzioni terapeutiche e 2) lavorare con concezioni di tempo diverse ma ugualmente importanti, e spesso in contrapposizione quando si cura l'Altro.

Attraverso l'analisi longitudinale delle interazioni momento-per-momento durante gli incontri di medicina high-tech tra un paziente, la sua famiglia e l'equipe medica, mostriamo come il framing e le diverse concezioni di tempo emergono come problemi, sono profondamente interconnessi e sono affrontati da coloro che curano il paziente che deve prendere decisioni esistenziali.

How to care for a person catapulted into a world that is unfamiliar, where the person confronts choices that infringe on the lived experiences and where the person's needs and queries are often in sharp contrast to those acknowledged by the dominant culture?

Educators continually confront this question, albeit in the specificity of each situation and community, when meeting first-generation students attending college, immigrant and migrant youth (Suárez-Orozco, 2004), and youth who do not experience familial and/ or cultural continuity (Miller et al., 2015). In science education, Glen Aikenhead (1996) depicts the powerful image of students who need to "border-cross" from their lived experiences into the subculture of science and science teaching to be able to learn science. In all the STEM disciplines, there is a long-lasting discussion on how to best implement what Gloria Ladson-Billings defines as culturally relevant pedagogy (1995) that is responsive to different ways of knowing (Gutiérrez \& Rogoff, 2003), inhabiting the world (Elmesky $\&$ Seiler, 2007) with religious beliefs (Roth, 1997), lived experience, cultural norms and values (Meyer \& Crawford, 2011) that are in contrast to those accepted in the scientific paradigms and classroom context (Mavuru \& Ramnarain, 2020). Cultural Studies of Science Education has been examining these issues since its foundation in 2006 by Kenneth Tobin and Wolff-Michael Roth.

In this paper, we discuss how similar issues are tackled by medical practitioners in the practice of high-tech medicine of Advanced Heart Failure (AdHF), when patients with malfunctioning hearts are confronted with the decisions to accept to live with the heart from another human being (heart transplantation) and/or with wearable mechanical circulatory 
support devices (e.g., a Total Artificial Heart, BiVAD) that can be at odds with the person's sense of what is acceptable. We do so by analyzing recorded data from moment-to-moment interactions and showing how tensions between the dominant Western medicine cultural paradigm (Cunningham \& Andrews, 1997) with its continually evolving high-technological and medical knowledge and the need to personalize care for the patient, as a person, are always at play and are continually emerging and in need to be resolved in the interactions of the AdHF medical team and patients and their families.

To better make sense of the context of AdHF, we start by taking the reader in the situation experienced by a patient, Mr. Spencer. We then develop our questions from this scenario.

Mr. Spencer sees his wife's face coming slowly into focus. Her voice, first a distant sound, becomes closer and louder as she yells, "Don't you leave me! Keep your eyes open, STAY AWAKE HONEY! DON'T YOU LEAVE ME!”.

Mr. Spencer is being resuscitated. He is in the Coronary Care Unit (CCU), diagnosed with a rare, aggressive and often fatal autoimmune disease, Giant Cell Myocarditis, that drove him into cardiac arrest, again. Being in CCU is a constant reminder of this experience and of the difficult choices, patients and families have to make. As Mr. Spencer recounts:

Mr. Spencer. Segment 1_ Every patient in the CCU unit has serious heart issues, so I was not the only person going Code Blue ${ }^{1}$ from time to time. The alarm and announcement occurred multiple times each day. "Code Blue! Code Blue! [...] Code Blue! Code Blue! [...]." We would hear people running down the hall. One night it was in the room next door. For nearly an hour we listened to the elevated voices calling out directives and continually re-announcing vital numbers. The frantic activity sent furniture or other heavy items crashing into the wall. The alarm and flashing lights continued for the duration. I grappled aloud with Tracy on how far do we go as Christians to scratch and claw at hanging on to this life when we know that this world is not our home. It weighed heavy on her when I expressed that I didn't want to be shocked and pounded and pumped incessantly like that.

( ${ }^{1}$ Code blue is an emergency announcement over a hospital's public address system requiring a team of healthcare providers to rush to the specific location and begin immediate resuscitative efforts of a patient in cardiopulmonary arrest.)

Western medicine with its study of organs and diseases that afflict patients' bodies is seen and understood in the modern cultural paradigm as a science and also as the practice in which a subject, the doctor, acts on the object, the patient's body (Timmermans \& Almeling, 2009). In this paradigm, issues of objectivity (Daston \& Galison, 2009) and objectification for the subject to understand, study and control things and other beings (Haraway, 1988) are considered important and necessary (Harding, 2015) but are incompatible with Mr. Spencer's agentic sense of being a person, not an object, and his aversion for overtreatment and potential futility (Clark, 2007) of high-tech medicine.

How to address Mr. Spencer's reluctance toward high-tech medicine treatments perceived as medical futility by him but not by his family? 
Mr. Spencer's Giant Cell Myocarditis disease developed suddenly. One day he was decorating the Christmas tree with his family, the next he was acutely falling ill and progressing toward AdHF. As per Guidelines Directed Medical Therapy for Giant Cell Myocarditis, Mr. Spencer has been treated with high doses of immunosuppressant medication. At the same time, in agreement with Mr. Spencer, the AdHF team has initiated the evaluation process for heart transplantation as a backup plan. Later, Mr. Spencer will recount about these days:

\section{Mr. Spencer. Segment 2. It is interesting how one gradually begins to accept things he would have never accepted before. For years I had reflected on the passing of my grandparents and others and was fairly adamant that I never wanted to be on life support. I certainly would not have been amenable to the idea of a heart transplant. When it was my time to go, I just wanted to be let go. Of course, I always figured that would come in my 80 's or 90's, not at the fresh age of 50 .}

Mr. Spencer has to yet come to terms with the idea of living with the heart from somebody else. In sociocultural terms as Margrit Shildrick (2011) puts it, "the heart stands in for a range of inherently human attributes [...] that are at the core of selfhood" (p. 234), which for Mr. Spencer includes a spiritual sense of self. As Federica Raia and Mario Deng (2015) discuss, the possibility of accepting the idea of heart transplantation becomes possible when one is compelled to uncover one's body as made of substitutable parts. In this process, "my heart" then transforms into a malfunctioning or broken "tool" that cannot support my life. Learning to accept "things [he] would have never accepted before" is now becoming part of Mr. Spencer's life experience.

How to frame the possibilities, the uncertainties, and course of the disease in high-tech AdHF in a meaningful context for Mr. Spencer confronting existential decisions?

Ethnographic work on caring for AdHF patients points to the ideological contradictions emerging from the competing needs to- on the one hand-objectify bodies and organs and - on the other hand-personalize care for the patient as a person (Sharp, 1995). Competing needs to personalize care for the patient as a person (Sharp, 2006) requires a multidimensional understanding of time (Raia, 2020). Indeed, a cohesive sense of a person's past and future possibilities, are both necessary to make sense of who we are and our actions in the present making the existential time nonlinear (Heidegger, 1962). However, within the modern cultural paradigm of science, and therefore in western medicine, time is one of the fundamental quantities, measured by a clock (clock-time) and is a linear progression from the past to the present into the future.

How to resolve the competing needs of the complementary concepts of clock-time and existential time to safely and meaningfully care for Mr. Spencer?

To address these questions, we highlight two issues: (1) framing the evidence-based knowledge of AdHF, uncertainties of the course of the disease and options for a meaningful decision-making process facing the patient, Mr. Spencer, and (2) Working with different, equally important and often at odds conceptions of time in the care for the Other. We discuss them below, reviewing some of the literature from different disciplinary perspectives that help us frame ours. After describing the research model, we present sequences of 
talk-in-interaction during two medical encounters between Mr. Spencer, his family, and the AdHF team. We ground our understanding in the study of how the issues of framing and different dimensions of time manifest in the moment-to-moment interactions and show that they are deeply interconnected.

\section{Framing}

The concept of framing, in its original formulation by Gregory Bateson (1972), serves to define context, organize perceptions of behavior, and shape how something makes sense to participants. Developing his concept of frame analysis, Erving Goffman (1974) suggests that people use frames to answer the basic question of "what is it that's going on here?" Since then, the concept has been utilized in different domains of social interactions.

In the learning sciences, situations in which professionals need to attend to the other's learning, such as in the interactions between teacher and students, framing is understood as the response to student thinking, as an attunement to, respect for, and engagement with intellectual resources students bring to bear in disciplinary contexts. In medical decisionmaking literature, framing is understood in a context of decision making, as organizing the possibilities of treatments and the choices a patient faces (Wirtz et al., 2006). It has been studied in primary care (e.g., Elwyn et al., 2012) and in oncology (Gattellari et al., 2002). These studies show that framing is often neglected or given too little time by practitioners in their interactions with patients. We tentatively adopt both definitions to study how framing is done in the moment-to-moment interactions, in which making-sense of a disease and therapeutic options require learning different medical concepts and a different language that is specific to the medical disciplinary context.

\section{Dimensions of time}

Wolff-Michael Roth, Kenneth Tobin and Stephen Ritchie (2008) show how classroom teaching and learning is mediated by different dimensions of time. Specifically, they identify not only misalignments between the temporally linear organization of the school day, and the way students and teachers experience and organize their activities, but that "rosters, deadlines and calendars, reporting periods, announcements on the PA by the principal, pre-lab activities and after-school activities, and being on time and being late create "temporal orientation, timing, pace, cycles, and rhythms" (p. 136). This time dimension, we call organizational, governs teachers' and students' experiences and possibility of success.

As we discussed above, clock-time is one of the fundamental quantities in science, measured by a clock with a linear progression from the past to the present into the future. As Raia (2020) discusses, the linearity of clock-time implies that the past has causal influence over the action of the present and the present over future action.

Existential time emerges from an individual's lived experience. In sociocultural theory, existential temporality has been explored in part through Lev Vygotsky's theory of play (Vygotsky, 1978) and Michael Cole's (2007) notion of prolepsis.

As Vygotsky discusses: "If human activity were limited to reproduction of the old, then the human being would be a creature oriented only to the past and would only be able to adapt to the future to the extent that it reproduced the past. It is precisely human creative activity that makes the human being a creature oriented toward the future, creating the 
future and thus altering his own present" (Vygotsky, 2004, p. 9). The child confronting the existential demands of becoming is always in dialogue with her future: "play gives a child a new form of desires. It teaches her to desire by relating her desires to a fictitious "I," to her role in the game and its rules. In this way, a child's greatest achievements are possible in play, achievements that tomorrow will become her basic level of real action and morality" (Vygotsky, 1978, p. 100).

In Cole's notion of prolepsis, a child is put always in dialogue with her future while confronting the existential demands of becoming, to make sense of how parents' expected goals for the future of their child constrain and guide their child's upbringing actions in the present. The nonlinearity of the process is introduced by the parents' culturally mediated, imagined future for their child. Both approaches assume cultural continuity (Cole, 2007, p. 239), while Raia's Relational Ontology (2020) focuses on caring-for-the-Other, catapulted into a world that is unfamiliar and threatening, does not assume cultural continuity. Indeed, she shows that to care for another, a professional needs to take into account not only a projection into future possibilities but also a past, no matter how disconnected it feels to the current situation. Building on Martin Heidegger's work, she shows that both are necessary because the past modulates the person's sensibility to attune to what is relevant to this person, and the future modulates the sense of possibilities of being this person. Indeed, a person's past and future possibilities together are necessary to make sense of the present, by organizing how things show up in the world as mattering in the present, and what it makes sense to do for this person. Specifically, Raia shows how the physician, in dialogic interactions, builds with and for the patient an existential temporal horizon: the physician recruits past events in the patient's life as salient for both the patient and physician and, after grounding the patient in a common relevant past, projects the patient into possibilities of being this person (future), he then returns to present actions in which the patient can inhabit a meaningful and shared present with the physician.

Within the Relational Ontology framework, Mr. Spencer's cohesive sense of the existential horizon is fragmented, when confronting death as the end of being in the world, and facing the world of AdHF, unfamiliar and disconnected from his existential past and projection into future possibilities of existing in the world. Based on this, we understand $\mathrm{Mr}$. Spencer's sense of meaningful engagement in activities with others in the current situation (present) developing as an existential crisis.

As discussed above, the possibility of accepting the idea of heart transplantation can be possible in situations of existential crises in AdHF (Raia and Deng, 2015). That is, when Mr. Spencer is compelled to uncover his body as made of substitutable parts, his heart transforms into a malfunctioning or broken "tool" that cannot support his life. Following Timothy Koschmann et al. (1998) who, building on Martin Heidegger, Aleksei Leont'ev and John Dewey, posit that a breakdown of fluent pragmatic doing is necessary to learn, Mr. Spencer's acceptance of "things [he] would have never accepted before" can be seen as a process of learning within the AdHF practice.

\section{Research model}

This work is part of an ongoing ethnographic and participatory research project studying the practices of teaching, learning and patient care in the high-tech medical practices of an AdHF program in a large US university hospital (Raia and Deng, 2015) with more 
than $500 \mathrm{~h}$ of recorded medical encounters between healthcare professionals $(n>25)$ and patients $(n>125)$ (IRB\#11-003,590).

The research model developed to study this practice (Raia, 2018) proceeds iteratively in three stages of data collection and analysis:

Stage 1: Encounter Recordings of AdHF medical encounters are longitudinally audio/ videotaped for a period of $1-4$ years.

Stage 2: Cogenerative dialoguing (cogen) (Roth and Tobin, 2004). Weekly video-/ audiotaped sessions with participating healthcare practitioners (co-authors here) whose interactions were recorded in Stage 1. Together participants and researchers review participants' taped interactions to make sense of their practices and discuss the emerging elements and themes. We report here parts of these weekly audio/video reviewing sessions (cogen session) in making sense of the data.

Stage 3: An ethnomethodological informed microethnographic (Erickson, 1996) analysis of the practice-recordings identifies the resources used by participants to organize their conduct and reciprocal accountability. Events identified by researchers and participants in Stage 2 are transcribed utilizing some of the transcription symbols (Sacks et al., 1974) reported below.

Although our analysis is based on collections encompassing multiple encounters from the data corpus, here we present a "single-case analysis" and report data from medical encounters of one of the 125 recorded patients, Mr. Spencer (pseudonym). This choice, as also Karen Lutfey and Douglas Maynard (1998, p. 323) discuss in their work on medical encounters, is consistent with Emanuel Schegloff's organization of analysis in which a range of phenomena from a larger corpus of "talk-in-interaction are brought to bear on the analytic explication of a single fragment of talk" (1987, p. 101). 
Transcription system

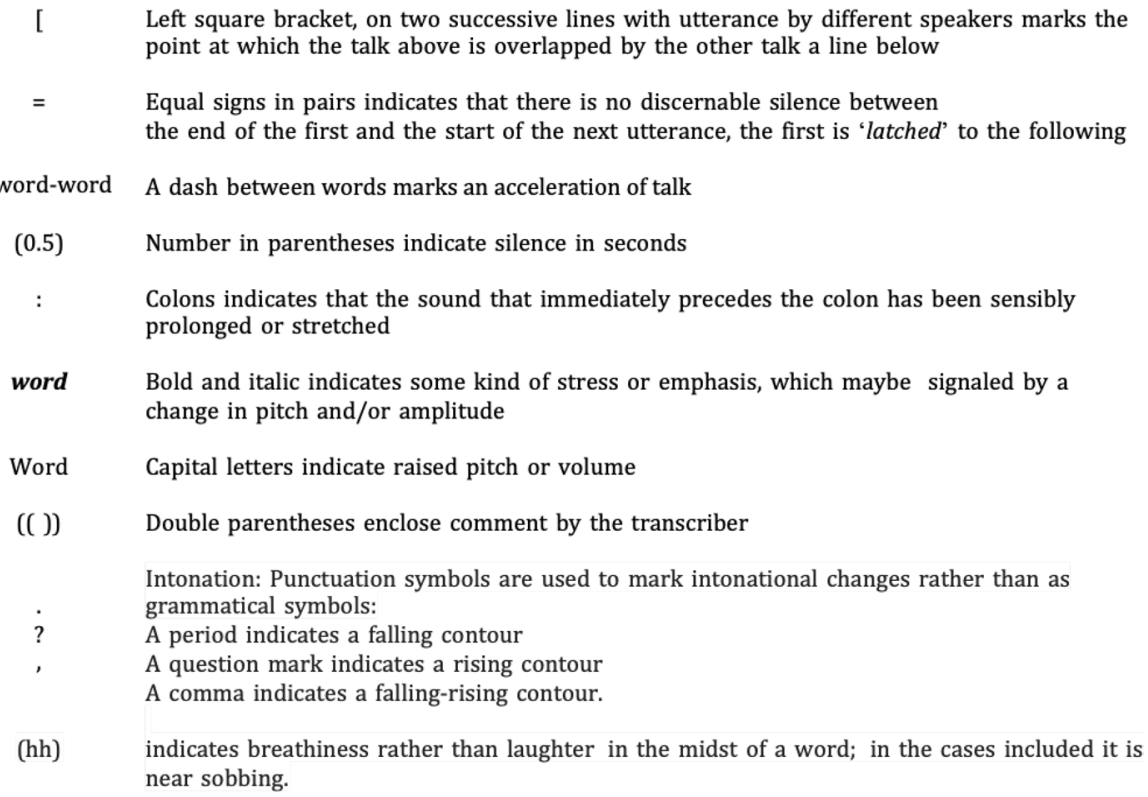

\section{Moment-to-moment interactions}

\section{December 29th}

The full case study of the data from our corpus is reported in Raia et al. (2021). Here we report two sets of data from two medical encounters with Mr. Spencer, bringing a new analysis of the data showing how issues of framing and different dimensions of time manifest in the moment-to-moment interactions and are deeply interconnected in the care for the Other. The first set shows how framing emerges in talk-in-interactions and is complexified by the needs of taking into account different dimensions of time. The second set shows the encounter with different healthcare professionals and how Mr. Spencer confronts choices, as shown in Fig. 1, that infringe on his lived experiences, needs and queries that are in sharp contrast to those acknowledged by the medical dominant culture, and how the participants resolve these tensions.

\section{Heart transplant waiting time is not an hour, a day, a week, a month}

This encounter introduces us to Dr. D, the AdHF attending, a cardiologist specialized in heart transplantation and mechanical assist device implantation who is conducting his 


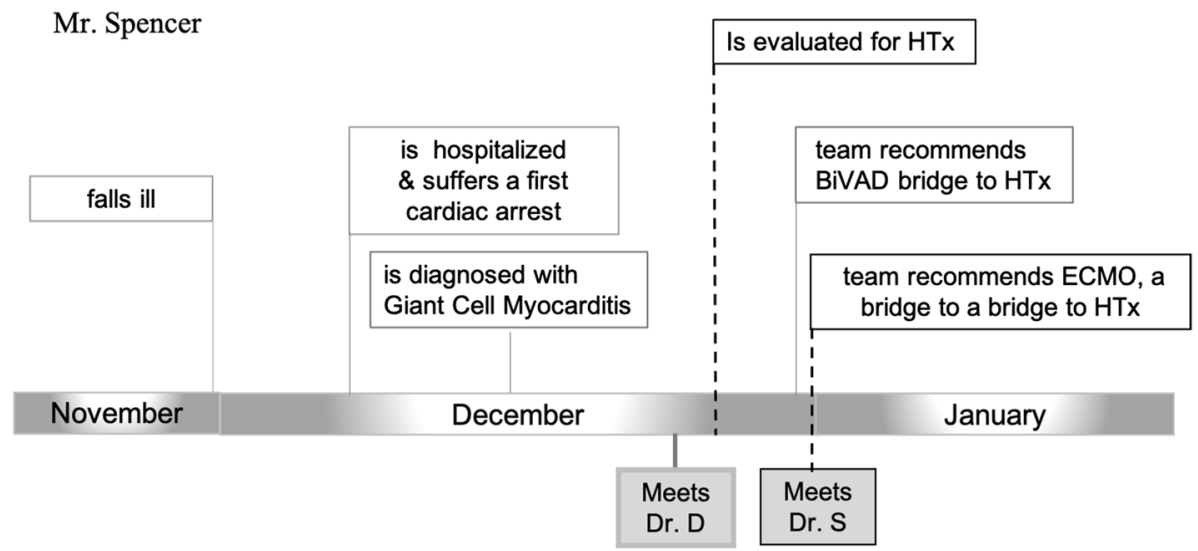

Fig. 1 Mr. Spencer's timeline. Mr. Spencer falls ill after Thanksgiving. In mid-December, a biopsy of the heart confirms Giant Cell myocarditis. Despite immunosuppression, Mr. Spencer's heart function worsens, and the team recommends evaluation for heart transplantation (HTx). At the end of December, the AdHF team recommends BiVAD implantation as a bridge to HTx. On New Year's Day, the team recommends ECMO as a short-term bridge to a long-term BVAD bridge to HTx. Thick dashed lines indicate the encounters we report here. Dr. D is a cardiologist specialized in AdHF, Dr. S is an AdHF surgeon

hospital rounds in the CCU accompanied by two trainees, the general cardiologist (GC) fellow and the AdHF fellow. They enter Mr. Spencer's room. It's December 29, and Mr. Spencer had suffered multiple episodes of arrhythmia. Mr. Spencer sits in his hospital bed, next to him stands his wife and CCU Nurse RN N. Dr. D discusses the recovery trajectory of Mr. Spencer's heart based on the results from the latest ultrasound rounding with him listen attentively:

\begin{tabular}{|c|c|}
\hline $\begin{array}{l}1 \text { Dr. D: } \\
2\end{array}$ & $\begin{array}{l}\text { when uhm we were in with the team uhm } \\
\text { we uhm uh were talking about }\end{array}$ \\
\hline 3 & from the update ultrasound $(0.7)$ \\
\hline 4 & it is not surprising that things aren't uhm (0.8) \\
\hline 5 & in-quotation-mark \\
\hline 6 & just turning around (0.8) \\
\hline 7 & it's uhm from the overall condition \\
\hline 8 & something that uhm (1.0) is u::h (1.2) \\
\hline 9 & gonna-be? (0.4) cha:llenging \\
\hline
\end{tabular}

There is no possibility of recovering Mr. Spencer's heart function. As the ultrasound results (line 3) show, things are not turning around (lines 4-6); the situation is challenging (line 9). Dr. D talks slowly with short acceleration (line 5), interspersed with hesitations ("uhm" lines 1, 2, 4, 7, and 8) suggestive of the talk's delicate nature (Silverman \& Peräkylä, 1990). Dr. D's slow but inexorable pace, the hesitations, and the number and the length of the notable silences ( $>0.4 \mathrm{~s}$ ) places a significant emphasis on the coming words. Prominence is given to the utterances "not surprising" (line 4), emphasizing the syllables. 
The pause after a fast uttered "gonna-be" (line 9) produces an effect of suspension marking, even more, the importance of what is uttered afterward: "cha:llenging" is followed by another pause, this time, marking the gravity of the situation: the possibility of recovering Mr. Spencer's heart function is vanishing.

10 Dr. D:

we will be uhm (1.4) intensifying the immunosuppressive therapy $(0.8) \mathrm{uhm}$ and uhm (0.6) we will continue to $(0.9)$ closely monitor? (1.2) uhm (1.4) but it's uhm

even in the b:est (.) possible scenario

as we said yesterday hum are uhm observing since you ca:me here and we started the therapy? (0.6) it's going to be some ((clears his voice)) first of all long term immunosuppression which is the least (1.0) of a problem but there is still (0.6) even at best possible immunosuppression l:ong term uhmm some limitations in (.) good outcomes in other words this transplantation option as a (.) close standby backup option (1.8)

Dr. D continues slowly to move toward the challenges ahead. Tracing back to the familiar step of immunosuppressive therapy to Mr. Spencer, Dr. D moves toward the challenges without mentioning them yet (lines 14-16). He moves in little increments, going back to familiar issues and then forthwith hesitations (e.g., "uhm" line 14). In silence or by clearing his voice (e.g., line 21), he pauses, pre-annunciating the importance of what is uttered afterward. What comes modifies what has been just uttered; the familiar immunosuppressive therapy, becomes long-term, the long-term therapy then becomes "the least of a problem" (line 23).

Lines 1-25 cumulatively point to Dr. D's involvement in the situation that is not just related to a decision-making process (Skelton et al., 2002) regarding what to do next with these new results or to minimize resistance to reach consensus (Robertson et al., 2011). Dr. D's talk (line 1-29) displays an emotional stance (M. Goodwin \& Goodwin, 2000) pointing to a participation in the disappointment that the option of transplantation is now closer (line 29) on the horizon with Mr. Spencer's heart function worsening, and Mr. Spencer's hope to retain his native heart is vanishing. 


\begin{tabular}{|c|c|}
\hline $30 \quad$ Dr. D: & the (.) problem being \\
\hline 31 & if for some reason we feel that things aren't heading the right direction \\
\hline 32 & from that time point on to \\
\hline 33 & transplantation \\
\hline 34 & is not (1.0) an hour period \\
\hline 35 & it's not (.) a day period \\
\hline 36 & it's not necessarily a week period \\
\hline 37 & it's not necessarily a month period \\
\hline 38 & the median waiting time for heart transplantation \\
\hline 39 & in this-region-of-the-United-States is three (.) point (.) zero $($.$) months$ \\
\hline 40 & which i:s [hospital name] \\
\hline 41 & which is the shortest in the country? for (.) population reasons $(0.9)$ \\
\hline 42 & and that is why then \\
\hline 43 & there may be this necessity of an additional bridge to transplantation \\
\hline 44 & if that medication isn't stable enough \\
\hline & (1.0) talking about these pumps (1.0) \\
\hline
\end{tabular}

Dr. $\mathrm{D}$ is at a very delicate point in the conversation. Introducing heart transplantation as a very close option brings other complications. With no heart function recovery, the option of heart transplantation includes the possibility of a bridge to heart transplantation via mechanical assist devices. With Mr. Spencer's worsening condition, the immunosuppressive therapy can no longer sustain his heart. The waiting period for heart transplantation can vary in time (lines 31-39). Dr. D slowly proceeds toward the challenges ahead. Being approved for heart transplantation requires waiting. The more hesitant talk we have on lines 10-25 for Mr. Spencer's vanishing hope of recovering gives way to a reciting voice (lines 34-37). The increments of clock-time attempt to measure a definite, yet unknown amount of time. The listener is taken into a rising and falling rhythm repeated each line 34-37 to admit the only certainty. There will be a waiting time. This waiting period is a liminal space for patients and their families, who often report that they are caught between hope for an offer of a donor heart, guilt knowing that the heart offer requires someone else's death and another family's tragedy and an ongoing concern about their current, fragile, status. Clock-time enters this space in a strident juxtaposition to existential time.

\section{Framing in practice}

The new development in Mr. Spencer's condition requires thinking more purposefully on how to reframe the scenario of a bridge to transplantation (line 43) by machine implantation, "these pumps" (line 45), i.e., the BiVAD, now looming on the horizon. It is an "open heart surgery" creating considerable anxiety in patients not only because of the procedure's complexity and potentially serious complications but also for fear that during the months of recovery their condition could worsen; they would die attached to a machine that is half inside and half outside their bodies before having a heart transplantation. 
Mr. Spencer: that makes (.) that makes (.) perfect sense to me (5.0)

\author{
you're basically saying
}

go ahead and put me on the list (1.8)

and then (2.0) ((clears his voice))

the only question would be ((clears his voice))

\section{I:f things came up earlier (1.2)}

and we weren't really sure whether this heart $(0.4)$

was going (0.5) to make it or not

we have to make a split second decision=

Dr. D: =that's brillia:nt thought $(0.6)$

For a person witnessing the dialogue, Dr. D's utterances such as "that is why then" (line 42) and "talking about these pumps" (line 45) would require an elaboration to be understood. Equally difficult to comprehend are the first lines 1-10 and all the references to the "list" to which Mr. Spencer also refers (line 49). Mr. Spencer's utterances, such as "if things come up earlier" (line 52), would require some elaboration for a casual witness to make sense of them; elaboration that we are providing based on ethnographic work. However, it makes perfect sense to both Dr. D and Mr. Spencer, who have the sense of "what is that's going on here" (Goffman, 1974). Dr. D has discussed the need for framing during the first visit as fundamental for the patient to learn to contextualize therapeutic options, uncertainties, and potential challenges that could present themselves in the patient's illness and life journey (Raia et al., 2021).

With the disease's erratic behavior, there is now a need to discuss, within the frame already in place, the possibility of a bridge to transplantation with machine implantations as a viable option. Dr. D does not interject during the five-second silence (line 47) at the end of Mr. Spencer's statement of agreement (line 46) nor during Mr. Spencer's numerous pauses. This muted request serves as an open invitation for Mr. Spencer to continue to talk after having introduced the transplantation option and is particularly noticeable because the silences on lines 49 and 52, like the one on line 47, are at the end of a finite statement and could signal to Dr. D that he should continue talking. An agreement as to what makes "perfect sense" is not enough to grasp "what's going on here," in Mr. Spencer's life. Deciding to accept heart transplantation is an existential choice, and the gravity of what has been said needs to be fully grasped.

Dr. D needs to care for Mr. Spencer (Raia, 2020), who is existentially shaken by the now very real possibility of losing his heart. What needs to be fully existentially grasped must start from what Mr. Spencer will say next.

"And then" (line 50) ... Mr. Spencer's doubt emerges. The two-second silence and the clearing of his voice emphasize what is uttered after "the question" remaining, Mr. Spencer clears his voice again. If the heart offer comes up too early (line 52), there is still some chance that his heart could recover (53-54). A "split-second decision" on a life-changing option must be made (line 55) to accept or not to accept the heart offer. 
Nuancing the discussion on making decisions within a much more complex context of uncertainty is a "brilliant thought" (line 56). But, what about the bridge to transplantation through machine implantation? Dr. D follows Mr. Spencer's lead. First to be discussed is "the split-second decision" uncertainty, a heart offer could come up "earlier" (line 52) when Mr. Spencer's heart function could still be sufficiently stable (lines 52-53).

\section{January 1 st}

\section{Difficult decisions}

Mr. Spencer's condition is deteriorating fast. A few days later, on New Year's Day, Mr. Spencer is facing the dreaded option of a bridge to transplantation-the implantation of machines (HVAD-BiVAD) surgery. Today he meets for the first time his AdHF surgeon, Dr. S. Together they discuss a new heart-ware HVAD-BiVAD that Mr. Spencer prefers over other types of BiVAD, the sequence of surgeries, and the machine implantation first and after recovery, heart transplantation. We enter in Mr. Spencer's CCU room when the AdHF team members are assembled around the bed: Dr. D, Dr. S, CCU nurse RN, AdHF Fellow, and Mr. Spencer's family: wife, brother, and father, standing beside. Dr. D is talking when Mr. Spencer shows irregular heartbeat. The situation is becoming urgent:

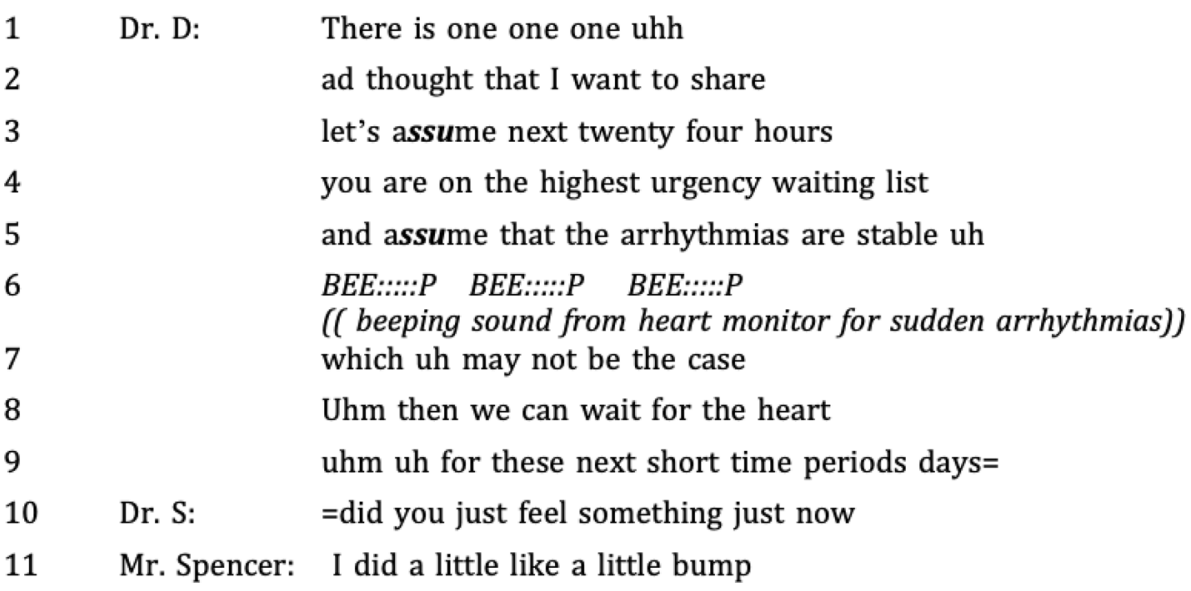

Dr. D is delineating the scenarios again. If arrhythmias remained stable (line 5), Dr. D was reasoning, but the loud piercing sound of the heart monitoring system alerted the room to the onset of new episodes of arrhythmias (ventricular tachycardia) (line 6). Dr. D repairs the sentence on line 5 with "which uh may not be the case" (line 7) and treads carefully not to exclude the possibility of waiting for a few days to see if a heart offer arrives while preparing for machine implantation (lines 12-15). A few days, a series of 24-h periods or the liminal waiting period for Mr. Spencer. Clock-time again enters this space in a strident juxtaposition to existential time.

Dr. S, who was inspecting the monitor latches into Dr. D's talk (line 10). Did Mr. Spencer feel the ventricular tachycardia (v-tach)? (line 10). He did; "a little bump" (line 11). The alarms marks Mr. Spencer's v-tach, his heart at 190 beats/minute; clock-time or existential threat for Mr. Spencer? There is a good chance that this unstable v-tach 
will degenerate into the potentially lethal ventricular fibrillation (v-fib). The team needs to consider an additional emergency but temporary step: have Mr. Spencer on an artificial heart and lung machine (ECMO). Dr. D resumes his talk:

12 Dr. D: yeah and if it's not stable and uhm

13 we are preparing for the mechanical support uhm

14 the preparation for the HVAD the uhm

15 implantable device just takes a bit=

16 Dr. S: =a little bit

17 Dr. D: and=

18 Dr. S: =lemme ask you one thing uhm if you do need need to go on ECMO though just to get to the a safe place to get you to the VAD would you have any issue with that cause that's not a that's something we need to address right now

Dr. D's talk is in stark contrast to the loud beeping sound of the alarm; he proceeds slowly, as if the situation, turning into a possible emergency, has no effect on his talk. He starts taking Mr. Spencer through the steps toward the prospect of needing an ECMO, pointing to the time it takes to prepare for BiVAD implantation surgery, a process of framing. It "just takes a bit" (line 15), but Dr. S intervenes (lines 16-18). As if in a relay race, he picks up the "bit" from Dr. D and runs with it. First with a calm but inadequately casual tone ("would you have any issue with that" line 21), not to alarm Mr. Spencer, as Dr. S discusses in cogen. Dr. S presents the prospect of going on ECMO a step "just" to get Mr. Spencer to a safe place (line 20); as if a simple decision on a preference and not on a significant component of life support can be made by Mr. Spencer. Then, with a sharp acceleration, Dr. S asks for an immediate verbal consent ("right now," line 23). The situation is escalating. Everybody can feel it in the room with the incessant beeping from the heart monitor. In cogen, both Dr. D and Dr. S recount their concern about Mr. Spencer's aversion to excessive medical interventions, and the impossibility of coming to terms with and agreeing to an ECMO if he coded because of v-fib.

Dr. S: you're constantly surveying a situation. At the beginning of this conversation, Mr. Spencer was discussing with me, and his vitals were stable. But with the occurrence of these events, you realize that the situation is changing. Mr. Spencer may arrest. You feel the urgency in my tone." Mr. Spencer could code, leaving the us physicians with only a slim opportunity to save his life. 
A similar perception and understanding of the situation was expressed by Dr. D and the CCU Nurse, who in cogen reflects:

I felt he [Mr. Spencer] was, he was going to die. I really felt it because his v-tach. His v-tach was very fast, and his hemodynamics were deteriorating.

Dr. S's recognition of the urgency in his tone indicates what, in that situation, is salient to him to highlight and how he interprets it. His emotional engagement on what matters to him is consistent with Raia's (2020) definition of existential time. CCU Nurse N brings together the fear of having her patient die (what matters to her, Raia, 2020) with a clock-time analysis monitoring the irregular heartbeat of Mr. Spencer, the bit bit bit rhythm measured in clock-time.

As we have shown in the beginning, Mr. Spencer is incessantly against an additional intervention - "bridge" procedure; he probes deeper:

In the event that ECMO is necessary, Mr. Spencer counts the three procedures, ECMO, VAD implantation and heart transplantation, whereas Dr. S reformulates them, framing them as one continuum: a bridge-to a bridge-to heart transplantation, and at the same time, caring for Mr. Spencer, orienting him toward a definitive therapy, heart transplantation.
37 Dr. S
it's it's
38
but if you if something happens to you and
39
your heart stops? and people are doing CPR?
40
one of the options to try to get you out of it?
41
chemically and with chest compressions? uh and
42
hope that you come back? and
43
the other option-if those don't and
44
then withdraw if things are not going the way that
45 we want them to:?
46 Mr. Spencer: o:r
47 Dr. S:
or we put you on ECMO and
48 that gives you a little bit of uh of time (.)

The situation can escalate, Dr. S continues: if Mr. Spencer's heart stops and he needs to be resuscitated one option is to try CPR (measured in compression per minute, clocktime), heart synchronization with defibrillation (i.e., electric shocks) and/or by chemical resuscitation. But then stop (withdraw, line 44) if there is no response. Or? Asks Mr. 
Spencer. "Or we put you on ECMO." That gives Mr. Spencer a bit more time. A few days at most that Mr. Spencer would remember as an eternity.

62 Mr. Spencer: no that's that's three (1.0) open heart (.) surgeries=

63 Dr. S: =it's-not-open-heart

64

it goes through your groin $(0.8)$

65

we do it through the groin uhm

66 Mr. Spencer: the pump hangs out of my leg

67 Dr. S: the the cannulas hang out

68 the pumps-at-the-bedside are much like your uh

69 looks something you know

70

like something like this size right here it it

71

I'm not so sure on ECMO you would even be aware it's there (.)

Mr. Spencer has often discussed his reservation with excessive intervention to save his life, as he did with his wife when he overheard the electrical shocks, and the incessant pounding to resuscitate a patient next door to him in CCU "how far do we go as Christians to scratch and claw at hanging on to this life when we know that this world is not our home." The ECMO implantation is for him an extra procedure, to get to transplantation, and one too many.

As if to plug gushing water, Dr. S rushes to utter the words ("=it's-not-open-heart" (line 63)) and amends Mr. Spencer' understanding that ECMO is another open heart surgery (line 62). But the pumps would be hanging out of his body, Mr. Spencer retorts. The cannulas, rectifies Dr. S, will be visible hanging out. Rushing the words "pumps-at-thebedside," Dr. S moves to show how small the pumps are to revise Mr. Spencer's perception. But maybe more is needed to convince Mr. Spencer that undergoing the ECMO procedure is essential to have a longer meaningful life with his family. Dr. S, as he commented in cogen, needs 'a nuclear option,' 'think about your family too: when you make a decision" (line 78). 


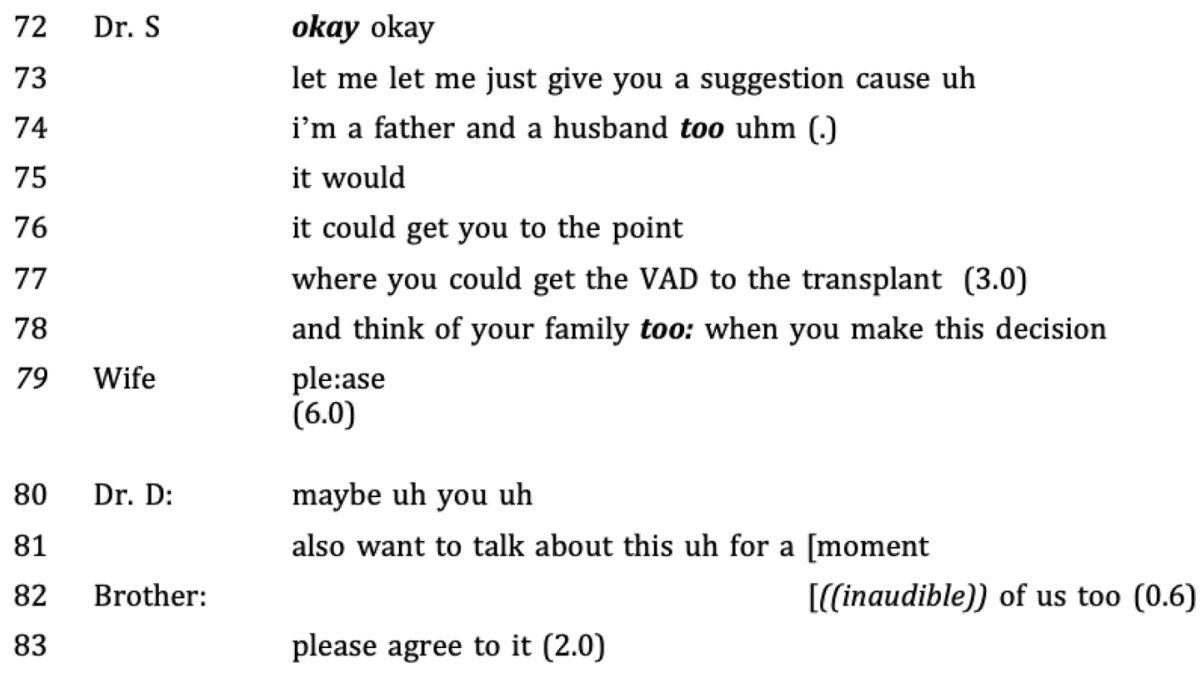

Dr. D supports Dr. S' move and calls on the family to speak more. The conversation continues with Dr. S clarifying to Mr. Spencer that the reason why he wants him to accept the possibility of an ECMO procedure is not because Mr. Spencer is unstable but on the account of the more complex preparation and the time required (up to $24 \mathrm{~h}$ ) to initiate the HVAD BiVAD implantations surgery.

Different dimensions of time are at play here. The altered beating of the heart (v-tach) measured in beats per minutes (clock-time) changes the mood in the room-all fear for Mr. Spencer's life including Mr. Spencer-and marks a change in the emotional response made visible by Dr. $\mathrm{S}$ acceleration of speech and rush into completion of consent.

In cogen, the two physicians comment further: 
Dr. S: In the back of my mind, I'm thinking this is a big undertaking. It could go awry. This could be terrible, it's the first one, and I'm advocating for something which I'd never done before. You know, we're going to do the best we can, which is bringing in the support of people who've seen it done before and can guide us and proctor us through this process. [...] As a surgeon, you have to figure out all this; and have to figure out how to portray confidence, but not cockiness, being upfront and forthright with the patient; confidence with full disclosure.

Dr. D: [...] At this part of the encounter, I feel like walking on eggs, you know- the two of us [Dr. D and Dr. S] think it should be done [agree to a possible ECMO implantation] and need to communicate it in a way that he [Mr. Spencer] doesn't shut off feeling he is pushed into authorizing what he may think are futile medical procedures. [..] My task is to deliver the patient to the surgical team in a meaningful way, that is, with an authentic decision made. Then I go home and have a glass of wine with my wife. Yes, it is really like the metaphor of the relay we discussed. Dr. S takes up from here. $\mathrm{He}$ calls home and says I'm not gonna be home tonight because I'm gonna spend the next eight hours in the operating room. So that's exactly how it feels.

Different time dimensions are also evident in the discussion in the cogen session. While Dr. D will measure time in existential time with his wife, Dr. S will not go home; he will spend eight hours in the operating room. Dr. S expresses also what Roth et al. (2008) describe as time imposed by institutional demands (we call organizational time). Implanting the new type of BiVAD will require Dr. $S$ to assemble a larger team to include personnel from the company that makes the HVAD BiVAD, to follow the FDA guidelines ensuring maximum patient safety. He needs time to organize the team for the surgery and make sure he has the consent from Mr. Spencer to proceed. Dr. S will need to take these actions as soon as he walks out of Mr. Spencer's room so that the surgery can be done by the evening.

For Dr. S caring for Mr. Spencer and "returning him to his family" is what matters. In Raia's Relational Ontology, the past and future possibilities of being organize how things show up in the world as mattering in the present. Dr. S' description expresses an existential temporality as also reported to Mr. Spencer in the encounter: 


\begin{tabular}{|c|c|}
\hline 95 Dr. S: & these are big undertakings I \\
\hline 96 & you know I have to assemble not just our team but \\
\hline 97 & I have to assemble the outside team \\
\hline 98 & that comes in too that helps manage these devices-it-is \\
\hline 99 & and as I said \\
\hline 100 & the right sided device is not something that \\
\hline 101 & $\begin{array}{l}\text { we have a lot of experience with } \\
\text { ((ECMO team enters }))\end{array}$ \\
\hline
\end{tabular}

\section{Unexpected disruptions}

Unexpectedly for Dr.S, Dr. D, Mr. Spencer and his family, the ECMO team enters the room (line 101). Its entrance could not have happened at a worse time, because, as shown on lines 101-105, not only does it interrupt Dr. S's explanation, but also, because the ECMO team is usually called when a patient has coded already and either had previously consented to an ECMO procedure or the consent process did not take place yet because the patient is incapable of consenting. This could suggest to Mr. Spencer that Dr. S and Dr. $\mathrm{D}$ are not taking into account his strong reservation against ECMO implantation. But Mr. Spencer has not coded and the doctors did not call the ECMO team.

With the entrance of the ECMO team, the speaker's orientation also changes from speaking to Mr. Spencer, into speaking to the ECMO team about Mr. Spencer. (e.g., Mr. Spencer "is talking to us," Dr. S insists, lines 107, 113, 120). In this situation, all participants have access to the conversation with the ECMO team. To show this change, we underlined the ECMO team members and those speaking to them (second columns in the transcript). 
102 Dr. S

103

104 ECMO Team:

105

106 ECMO Team:

107 Dr. S:

108 ECMO M1:

109 ECMO M2:

110 ECMO M3:

111 ECMO M2:

112 ECM0 M1:

113 Dr. S:

114 ECMO M2:

115

116

117

118

119 Dr. S:

120

121

122

123 Mr. Spencer:

124 ECMO M3:

125 AdHF Fellow:

126 Dr. D:

127 ECMO M3:

128 ECMO M2:

129 Dr. S:

130 Dr. D:

131 Mr. Spencer: because it just hasn't been used for that ((ECMO team talks to CCU Nurse $N$ in the back ground)) [it's it's like using uh

[((inaudible $)$ )

[it's it's it's

[we need shock him out of it

he's TAlking to us

(( turns to ECMO team))

just a second let us take a look at here

I think we should have art-line

yea

just so you we know

yeah

but he's TALKing to us really

I just gonna ATP him

((inaudible))

is this the most recent pressure for the cycle

I just did one

I'll do another one

Look at the heart wave form he clearly perfuses

he is talking

he said some sentences with this pressure

I don't think you wanna (.) leave him in this

hrh hrh ((clears his throat))

Did it just start now

yeah while we were talking about it

Uh uh

Are you guys scaring him?

eh eh

No he had the

I think we are scaring you

no:hh ((crying))

Upon entry into Mr. Spencer's room, the ECMO team confirms the emergency character of the situation wanting to shock Mr. Spencer to restore his heart rhythm (line 106), place an arterial line (art-line line 109) and initiate an anti-tachycardia-pacing (ATP-line, line 114). At the same time, the ECMO team needs to acknowledge that Dr. S is correct, something must be stable and not emergency-like requiring the three actions (lines 106, 
109, and 114) immediately. Dr. S repeats three times that Mr. Spencer “ is TALKing to us" (line 107) "but he's TALKing to us really" (line 113), "he is talking" (line 120), indeed Mr. Spencer did not code! "Look at the heart wave" urges Dr. S to the ECMO team interpreting it as the sign of good perfusion (line 119). Yes, the waveform (the heart rhythm) trumps Mr. Spencer talking to the team in the interpretation of Mr. Spencer's ability to be present and capable of decision making.

The ECMO team continues talking with Dr. S and CCU Nurse N. In the meantime, Dr. D talks to Mr. Spencer and his family. Here, the pronoun "we" changes from "we", the hospitals teams, "are scaring you," Mr. Spencer (line 130) into indicating "we" Mr. Spencer and the AdHF team, "we have a decision in place" (line 133): 
132 Dr. D: I would think that would be part of the situation

133

134

the important thing is

135

we have decisions in place

136

137

on the listing now that'll be formalized

138

number two

139

we have a decision in place of biventricular assist device

140 that should be if possible HVAD BiVAD

141

what we're right now discussing is

the ti:me to assemble everything will take so:me

142

143

144

and if we don't have the time uh

145

we have right now available a PVAD BiVAD but

those hang out of the body:

you have a statement in place that you don't want tha:t

146

we have

147

148

149

if more urgently bridging to either of these two

150

151

152

153

a VA-ECMO required currently a thought that uh

you would not want that

uhm this is by the way

the VA-ECMO is not the type of assist heart pump surgery

that of size of a uhm mechanical support or heart transplant

it's mo:re as we call it a big catheter based uh approach

So it's this uh

154

it doesn't have the same quality and

155

156

157

158

159

it's only for a few da:ys to uh have that longer term pump in place that would be an important in my opinion

a very favorable decision to make to uh uh to accept that

but uhm just from my perspective

160

it's not the same like three uh stage to heart transplant

it's um [VA-ECMO you know

[BE::::

$B E:::: \quad B E:::: \quad B E::::$

From line 134 to 142 , Dr. D uses the pronoun "we" to include Mr. Spencer, his family and the AdHF team to summarize all the important decisions in place (i.e., lines 134, $137,139,141,142)$. First, to accept heart transplantation ("being on the list" line 135). "Number two" (line 136), the decision to have a bridge to transplantation via biventricular assist device. Rather than having visual access to the blood rotating into the pumps, which Mr. Spencer would have if he had chosen the PVAD BiVAD implantation, Mr. Spencer prefers the HVAD BiVAD because the actual pumps are implanted inside the body (lines 137-141). At lines 144 and 148, Dr. D isolates Mr. Spencer's preference (you). The first 
time, line 144, points to the choice between PVAD BiVAD and HVAD BiVAD, the PVAD BiVAD requiring less preparation and organization and therefore less time during which Mr. Spencer can develop more arrhythmias. The second time (line 148) is the discussion about a possible ECMO procedure. In highlighting Mr. Spencer's preference "you” Dr. D voices to Mr. Spencer that his preferences are acknowledged, however, having defined the second "currently a thought" (line 147) Mr. Spencer's rejection of a possible ECMO procedure is not yet accepted as the final decision by the doctor.

Dr. D continues. He supports Dr. S's description, downsizing the ECMO implantation in comparison with HVAD-BiVAD implantation and heart transplantation. He defines it as a catheter procedure (149-154), and therefore, as Dr. S has done, frames Mr. Spencer's understanding of a three-stage procedure rather than two (BiVAD implantation with possible ECMO as a bridge to transplantation) or even one a bridge to a bridge to transplantation. By highlighting Mr. Spencer's preferences first and then at lines 155-156 and 157 stating his opinion, Dr. D points to the role distribution, a patient who has the right of making a final decision in consultation with a professional who needs to state his/her professional advice and therefore defining this process as a shared decision-making process. Dr. D expresses his assessment of the acceptance of the possibility of ECMO implantations as "a very favorable decision" (line 157).

After Dr. D's words, the intensity of the situation seems to have lost the turbulence generated by the sudden entry of the ECMO team, however as a coda, the loud sound of a beeper suddenly erupts, the ECMO team enters the conversation with Mr. Spencer putting electrodes on his chest and side (lines 160-162), the defibrillator's mechanical voice speaks the automated words: backup without signs of compression backup without signs of compression, bit bit bit the heart monitor marks the accelerated heart beats generated by a new v-tach episode. 
161 ECMO M2: we are putting them as a back-up now? backup without signs of compression

We are not planning to give you shock?

backup without signs of compression

163 Dr. D:

(hhH)HHH ((deep loud sighs))

164 CCU Nurse N: just putting them on

bit bit bit bit bit bit bit bit

165 Dr. D: (hhH)HHH share your thoughts anytime (hh)hh

bit bit bit bit bit bit bit bit bit

166 I now want us to (.) work through this you know

167 Mr. Spencer: I don't want (hh) ((as if about to cry))

168 stuff hanging out uh

bit bit bit bit bit bit bit bit bit

169

except for an electrical cord or

bit bit bit bit bit bit bit bit

170

that that's why that's acceptable

bit bit bit bit bit bit bit bit bit

171

it would let me go home (0.4) for a while

bit bit bit bit bit bit bit bit bit

172 Dr. D: yes

bit bit bit bit bit bit bit bit

173 Mr. Spencer: till we had a transplant and have a somewhat normal life= bit bit bit bit bit bit bit bit

174 Dr. D: =the HVAD BiVAD absolutely=

bit bit bit $\quad$ bit bit bit $\quad$ bit bit bit

bit bit bit bit bit bit bit bit bit. The 3 bits per second sound of ventricular tachycardia (v-tach) now is ongoing and clearly audible via the audio signal of the heart rhythm motor. The situation can turn into an emergency if the v-tach does not dissipate quickly as it did before. Dr. D's sighs (lines 163 and 165) are deep, as if conveying the gravity of what 
is happening. Dr. D asks Mr. Spencer to share his thoughts, "I now want us to (.) work through this you know" (line 166) as, he had share in cogen "to deliver to the surgical team the patient in a meaningful way that is with an authentic decision made." Together they review the decisions in place once again: Mr. Spencer does not want to see the pumps pumping his blood outside his body; the electrical cord will connect the pumps inside his body to the batteries and computers (lines 168-169). He wants to be able to go home (line 171) and recover there with a somewhat normal life (line 173). Dr. D immediately translates Mr. Spencer's decision into the available choice: the HVAD BiVAD, emphasizing they are in agreement (yes, line 172; absolutely, line 174).

\section{A faster pace, a reorganization of communication spaces}

Dr. S joins Dr. D and Mr. Spencer. Dr. S intervenes (line 176), overlapping first with Mr. Spencer (lines 176) and then with Dr. D (line omitted) to describe the ECMO. However, Mr. Spencer is not interested in what the device is. He is interested in how the device impacts his short- and long-term life:

189 Mr. Spencer: i'm laying flat on my back the whole time?

190 Dr. S: you cannot walk with them

191 you're absolutely right

192 you lay on your back uhm

Dr. S starts answering Mr. Spencer's question; however, bit bit bit bit bit bit bit bit bit, the ventricular tachycardia (v-tach) does not stop. The urgent situation turns into an emergency. 


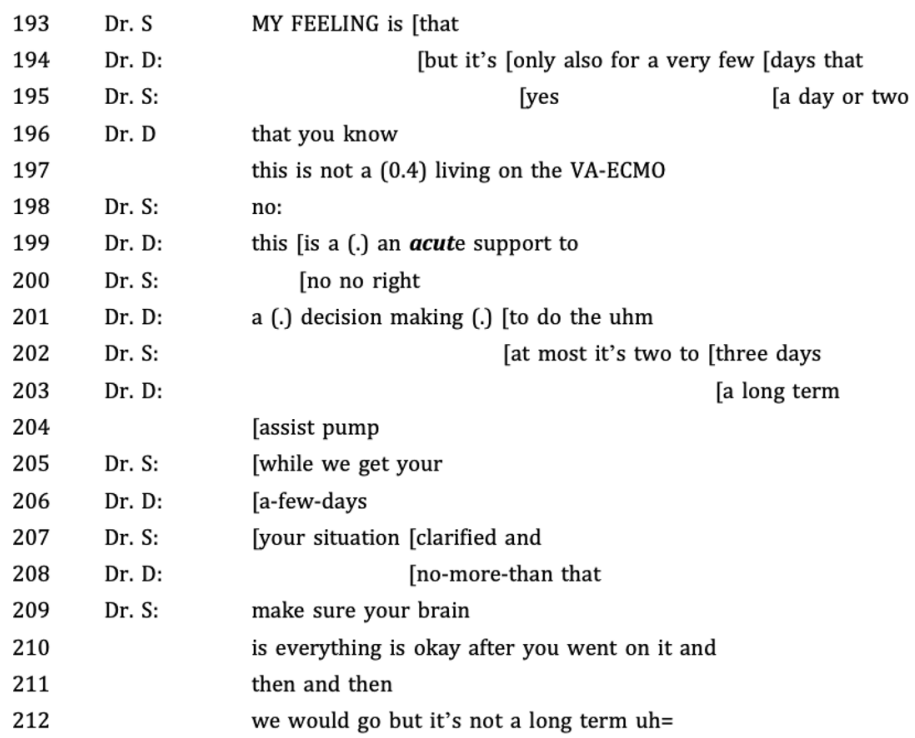

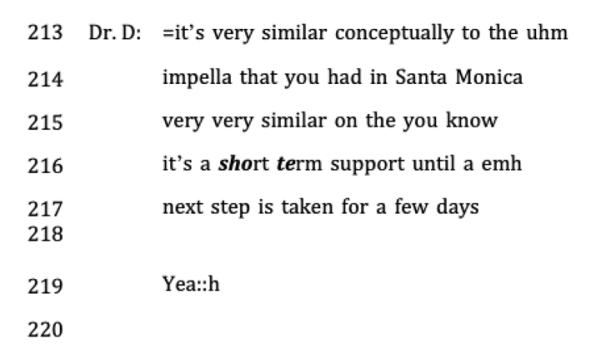

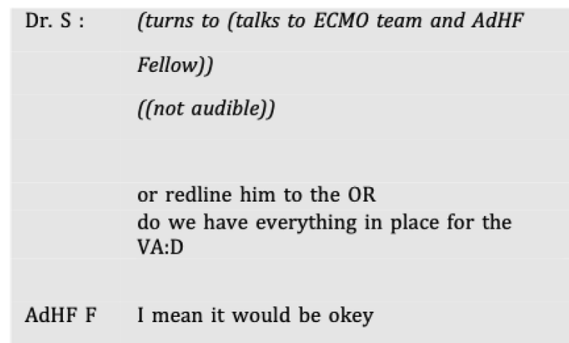

$\begin{array}{lll}221 & \text { Dr. S: } & \text { Do we have all the administrative stuff in place? } \\ 222 & \text { Dr. D: } & \text { Yes yes that's in place }\end{array}$

Both Dr. D and Dr. S act immediately as they are used to in their respective practices, taking charge in an emergency. Their overlaps show their moves. Dr. S suspends answering Mr. Spencer's question and with a loud voice is shifting into a higher gear, moves fast into convincing Mr. Spencer of the benefit of the ECMO. Dr. D does the same. The apparent competition for the lead fast resolves in organized teamwork: Dr. D talks to Mr. Spencer and his family in what Goffman (1974) defined as a frontstage, while Dr. $\mathrm{S}$ organizes the plan in backstage, where Mr. Spencer and his family have no auditory access, a common division of space in medical care (Raia \& Smith, 2020). A sudden change of a situation, from urgent to emergency, requires multiple rapid adjustments. 
du:::m du:::m du:::m du:::m du::::m du:::m du:::m du:::m du:::m du:::m du:::m $d u::: m$ du:::m

224 ECMO: I don't want to leave him in this?

226 CCU Nurse: Would you like it in V1

$B E::: B E:::: B E::::$

bit bit bit bit bit bit bit bit

227 Mr. Spencer: I haven't changed my mind

bit bit bit bit bit bit bit bit bit

228 ECMO :

Ok starting ATP guys

bit bit bit du:m bit bit bit du:m bit bit bit du:m bit bit bit du:m bit bit du:m

DU:::M DU::::M DU:::M DU:::M DU::::M DU:::M DU:::M DU::::M DU:::M DU:::M DU:: $D U::: M$ DU:::M

Hu:r Hu:r Hu: Hu: Hu:

$B E::: B E::: B E:::$

229 Dr. D: $\quad$ would you like a (.) moment with wife and dad without us being here

230 Mr. Spencer: Uhm (10.0) (( the reast of the team talk to ecmo team in the background))

231

232

233

234

235

236

237

238

239

240

241

242 I don't I don't necessarily want you guys to leave cause you're watching over my stability right now Dr. D: $\quad$ yes that's right

Mr. Spencer: so what

Dr. D: $\quad$ or uhm maybe we could just uh can you both maybe also just share your thoughts ((addresses family)) come here yeah ((team talking in the background)) we can we can use this moment to to uh respecting whatever you want to be done (( to Mr. Spencer)) to go through this right now we have we have all the ti:me you know?

The ECMO team charges the machine (line 223) to deliver electrical pacing impulses that are 10 bits/minute faster than Mr. Spencer's v-tach heart rate (Anti-TachycardiaPacing, ATP, line 225). The emergency situation does not change Mr. Spencer's mind about the ECMO procedure (line 227). The ECMO team proceeds to ATP (line 228). The v-tach stops. For now.

Dr. D asks Mr. Spencer if he would like a moment alone with his family (line 230). Mr. Spencer's wife and brother have already voiced their hope that Mr. Spencer would accept the ECMO procedure if necessary (lines 79 and 83). As Dr. D reflects in cogen, alone with the members of his family, Mr. Spencer would feel in a safe and trusted existential space where he does not feel pressured by the presence of and intervention by the AdHF team. But Mr. Spencer is scared to be left without medical supervision, watching over his stability (lines 231-232) and Dr. D repairs his action by inviting the family, who had retreated from the bed during the work of the ECMO team, to come back closer to Mr. Spencer, share their thoughts with the promise of respecting Mr. Spencer 
preferences and supporting him in a shared decision-making process; "we have all the time, you know?".

Mr. Spencer's wife commented on that moment as follows:

He [Mr. Spencer] didn't want the the mechanical heart support [ECMO] and the family all decided to pray around him. Dr. D put his hand on [Mr. Spencer] 's arm and he stood there with us and he just waited for us to have that time together praying. His presence was just there the whole time. Very, very supportive. And I think that the decision had a lot to do with it.

\section{Contra-punctual tempo}

In cogen session, Dr. D comments:

Listening to this sentence, "we have all the time" I feel myself in that situation, trying to create an atmosphere where Mr. Spencer feels in a space that is not rushed, not driven, not motivated by the fear of dying and the associated anxiety in the team; the urgency, the indicators like the alarms and the behavior of people talking about the illnesses as opposed to talking about it with him. So I'm seeing myself actively creating a contra-punctual atmosphere; is like Joan Sebastian Bach's composition.

Dr. D contrasts clock-time with existential time as elements that are in contrast but all part of one composition. Dr. D continues:

It is interesting to see myself working on this. Just take what we just listen to, those five sentences [lines 136-241]. The last one of these is "we have all the time" [line 241], which is absurd; we have no time because right now he is dying. The sentence before is "respecting whatever you want" [line 239], and the sentence before this one is to his father, brother, and wife to stand by next to him. They were basically paralyzed and not interacting with him. So, I'm trying to ease them into saying something to this patient who is at risk of dying right now. The sentence before this is "share your thoughts" [line 236]. It's the first of the five. I went backward. "Share your thoughts," it is so important for me to listen to this; my voice is a contrapunctual to everything else that's going on. It's the opposite of the high pitch of all the alarms and alarmed voices. I am trying to own the space with the patient that allows for some existential and spiritual connections and against the gradient of the emergency.

The Resident doctor participating in cogen responds to $\operatorname{Dr}$. $D$ : 
I totally agree. In this moment, Dr. S and the ECMO team, like everyone else, are moving in one direction: start ECMO! Save the patient! Like: we don't have ANY time. Dr. D and the patient are taking a moment, a different direction. The sentence 'we have all the time' was so funny to me; my heart rate started speeding up; even just listening to the situation, I felt like, there is no time! We have no time! Dr. D takes the power because he's making time, as if there was time, 'we are creating time' on the basis of the patient's values, dying versus getting a procedure against his will.

You [Dr. D] are balancing that all. I think it speaks to how well you [Dr. D] understand the patient, you know, and I also think the patient signals to you that he understands how seriously ill he is, and you listen. A lot of docs would think that the patient doesn't get it, you know because he is blocking a potentially lifesaving procedure. But Mr. Spencer understands; he says I don't think you should leave the room because you're watching over me because I'm unstable. So, he signals to you that he gets it, you get it. And the patient has the power to stop [the procedure]. So, both you and the patient are having the power in this moment because every other physician and nurse in that room are like, 'Go! Go! Go!' preparing for that moment, and the patient is saying: 'I'm not sure yet.'

Saying 'we have all the time' honestly almost makes you laugh in a way because it's so ... In a doctor-centered perspective, it's so crazy to say that because we don't have time. In the doctor's typical perception, it's like: we have to save this person's life, and we don't have that much time. The way we cope with that stress is to do something, you know, and they're all moving towards that, and it takes a lot to stop that momentum, yeah, and create that space. So, it is in contrast to everyone else's pace in the room; and also like me as a listener, because even me as a listener, I'm like, oh my God, he's going to code right there if we don't start ECMO. I know listening to this, I, I can't imagine doing what you did in this moment because I still have, I just feel the adrenaline. I think that would be really hard to do in that moment for me. I think it's very impressive.

\section{More than an epistemologically defined professional vision}

The above discussion among the healthcare professionals in cogen unpacks for us different aspects important for our discussion of the two encounters. Doctors at different stages of training (Resident, Fellow, and Attending) highlight the situation as relevant, pausing the recording to comment on this moment. They all code the situation as very urgent with the possibility of degenerating into an emergency, expressing a similar professional vision as previously defined by Charles Goodwin (1994). However, the emotional responses are different. While the Resident and the Cardiology Fellow, feeling the adrenaline rising, are drawn into the room's emergency mood, the AdHF Attending, Dr. D, acts differently. The Resident describes Dr. D's counter-punctual move to the emergency mood as "stopping that momentum" that was drawing all, including the Resident, into an emergency mood. Both the Resident and Fellow also recognize Dr. D's act as something that they have not yet mastered and a "very impressive" skill that helps the patient partake in a shared decision-making process. 
When the emergency situation unfolds, both Dr. D and Dr. S act immediately as they are used to in their respective practices, taking charge in an emergency. They similarly highlight and code a change in the situation from urgent to emergency. What the Resident describes as the immediate stress reaction to a possible emergency "is do something," translates for the Attendings into immediately taking the lead of the situation. In this boundary space, the sudden change of a situation, from urgent to emergency, requires multiple rapid adjustments which resolve the apparent competition and moves the focus from the individual professional's capacity and skills to a teamwork context: Dr. D talks to Mr. Spencer and his family, while Dr. S organizes the plan. Within the larger background context of caring for Mr. Spencer, the local organization of the two professionals' responses is organized not only by what they highlight and how they code the situation at hand but, as Raia et al. (2021) discuss, also according to the diversified professional goals and anticipated actions. Dr. D's goal, as he has expressed above "is to deliver to the surgical team the patient in a meaningful way that is with an authentic decision made." Dr. S's goal is to consent Mr. Spencer and to immediately start the preparation for surgery, making sure that the procedure is safe and has a successful outcome.

The fast reorganization and division of backstage and frontstage activities shows how well Dr. S and Dr. D know how to rely on each other and support their respective professional goals and needs, which combined provide the care Mr. Spencer needs. Dr. S and Dr. $\mathrm{D}$ have been working closely together for some years, with the shared background of caring for the patient, they continuously monitor each other's differential actions, making sure they contribute to the complementary final goal of care. It is this cooperation that allows Dr. D to take a counter-punctual stream of actions that ensure that Mr. Spencer can have a safe space where to share his thoughts and pray with his family in a decisive moment of his care. It is based on this that Dr. S, as he also discussed in cogen, could, a few moments later, leave Mr. Spencer's CCU room to come back after Mr. Spencer and his family under the supervision of Dr. D had time to talk and pray together.

\section{Framing-for and-with the other}

Dr. D's particular counter-punctual move can only be successfully accomplished because in the past days Dr. D, Mr. Spencer and his family have built trustful relations through the process of framing-for and -with the Other. Dr. D, Mr. Spencer and his family together have confronted numerous uncertainties. Jürgen Kasper et al. (2008) identify multiple sources of uncertainty pertaining to: diagnoses, prognoses, and treatment of disease; patient's preferred degree of involvement, issues of patient social integration, and mastering of life requirements; and physician's competence and trustworthiness- which includes how information about risk is provided and how the patient deciphers it. Throughout the excerpts of two days, we have seen how Dr. D framed-for and-with Mr. Spencer these uncertainties, centering them around Mr. Spencer's expectations and existential queries. By analyzing talk-in-interaction, we showed how Mr. Spencer and Dr. D implicitly refer to previous acts of framing in their conversation. However, Dr. D did not only attend to Mr. Spencer's thinking or to his intellectual understanding of options and procedures but is caring for Mr. Spencer (Raia, 2020) as a person who is existentially shaken by the very real possibility of losing his heart, losing his way of life and facing death. Dr. D's acts of care can be accomplished by the doctor's talk, punctuated by silences and repetitions, creating an existential space in which Mr. Spencer's doubts on new uncertainties and complex options can emerge 
and be discussed and framed for and with Mr. Spencer in the moment. On New Year's Day, new uncertainties emerge: having to possibly receive an emergency bridge to a bridge to transplantation (ECMO), and meeting his surgeon for the first time and a need to assess the physician's competence and trustworthiness (Kasper et al., 2008). During the escalation from urgency to emergency situation, Dr. D creates again a space for Mr. Spencer's needs where there is "all the time" for Mr. Spencer to be able to pray with his family. Indeed, Dr. D creating a space for Mr. Spencer and his family to be able to pray, and partaking in it as a professional, identifies Mr. Spencer's spiritual life as salient. It is an existential past modulating Mr. Spencer's sensibility to attune to what is relevant to him, and a future sense of possibilities of being himself so that Mr. Spencer can inhabit a meaningful and shared present with the physician to face the decision to accept an ECMO.

To care-for-the-other, catapulted into a world that is unfamiliar, where the person confronts choices that infringe on the lived experiences and where the person's needs and queries are often in sharp contrast to those acknowledged by the dominant culture required all participants to admit a complementarity of existential, organizational and clock-time in medical practice to help the person, Mr. Spencer, to be able to make sense of "what is that's going on here" and support more complex professional visions of different team members.

Open Access This article is licensed under a Creative Commons Attribution 4.0 International License, which permits use, sharing, adaptation, distribution and reproduction in any medium or format, as long as you give appropriate credit to the original author(s) and the source, provide a link to the Creative Commons licence, and indicate if changes were made. The images or other third party material in this article are included in the article's Creative Commons licence, unless indicated otherwise in a credit line to the material. If material is not included in the article's Creative Commons licence and your intended use is not permitted by statutory regulation or exceeds the permitted use, you will need to obtain permission directly from the copyright holder. To view a copy of this licence, visit http://creativecommons.org/licenses/by/4.0/.

\section{References}

Aikenhead, G. S. (1996). Science education: Border crossing into the subculture of science. Studies in Science Education, 27(1), 1-52. https://doi.org/10.1080/03057269608560077

Bateson, G. (1972). Steps to an ecology of mind. New York: Ballantine.

Clark, P. A. (2007). Medical futility: Legal and ethical analysis. AMA Journal of Ethics, 9(5), 375-383. https://doi.org/10.1001/virtualmentor.2007.9.5.msoc1-0705

Cole, M. (2007). Phylogeny and cultural history in ontogeny. Journal of Physiology-Paris, 101(4), $236-246$. https://doi.org/10.1016/j.jphysparis.2007.11.007

Cunningham, A., \& Andrews, B. (1997). Western medicine as contested knowledge. Manchester: Manchester University Press.

Daston, L., \& Galison, P. (2009). Objectivity. New York: Zone Books.

Elmesky, R., \& Seiler, G. (2007). Movement expressiveness, solidarity and the (re)shaping of African American students' scientific identities. Cultural Studies of Science Education, 2(1), 73-103. https:// doi.org/10.1007/s11422-007-9050-4

Elwyn, G., Frosch, D., Thomson, R., Joseph-Williams, N., Lloyd, A., Kinnersley, P., Cording, E., Tomson, D., Dodd, C., Rollnick, S., Edwards, A., \& Barry, M. (2012). Shared decision making: A model for clinical practice. Journal of General Internal Medicine, 27(10), 1361-1367. https://doi.org/10.1007/ s11606-012-2077-6

Erickson, F. (1996). Ethnographic microanalysis. In N. F. Hornberger \& M. H. Long (Eds.), Sociolinguistics and language teaching. (pp. 283-306). Cambridge: Cambridge University Press.

Gattellari, M., Voigt, K. J., Butow, P. N., \& Tattersall, M. H. N. (2002). When the treatment goal is not cure: Are cancer patients equipped to make informed decisions? Journal of Clinical Oncology, 20(2), 503-513. https://doi.org/10.1200/JCO.2002.20.2.503 
Goffman, E. (1974). Frame analysis: An essay on the organization of experience. Cambridge: Harvard University Press.

Goodwin, C. (1994). Professional vision. American Anthropologist, 96(3), 606-633. https://doi.org/10. 1525/aa.1994.96.3.02a00100

Goodwin, M., \& Goodwin, C. (2000). Emotion within situated activity. Communication: An Arena of Development, 33, 54

Gutiérrez, K. D., \& Rogoff, B. (2003). Cultural ways of learning: Individual traits or repertoires of practice. Educational Researcher, 32(5), 19-25. https://doi.org/10.3102/0013189X032005019

Haraway, D. (1988). Situated knowledges: The science question in feminism and the privilege of partial perspective. Feminist Studies, 14(3), 575-599. https://doi.org/10.2307/3178066

Harding, S. (2015). Objectivity and diversity: Another logic of scientific research. Chicago: University of Chicago Press.

Heidegger, M. (1962). Being and time (J. Macquarrie \& E. Robinson, Trans.). Amsterdam: Blackwell Publishing.

Kasper, J., Geiger, F., Freiberger, S., \& Schmidt, A. (2008). Decision-related uncertainties perceived by people with cancer-Modelling the subject of shared decision making. Psycho-Oncology, 17(1), 42-48. https://doi.org/10.1002/pon.1190

Koschmann, T., Kuutti, K., \& Hickman, L. (1998). The Concept of breakdown in Heidegger, Leont'ev, and Dewey and its implications for education. Mind, Culture, and Activity, 5(1), 25-41. https://doi. org/10.1207/s15327884mca0501_3

Ladson-Billings, G. (1995). Toward a theory of culturally relevant pedagogy. American Educational Research Journal, 32(3), 465-491

Lutfey, K., \& Maynard, D. W. (1998). Bad news in oncology: How physician and patient talk about death and dying without using those words. Social Psychology Quarterly, 61(4), 321. https://doi. org/10.2307/2787033

Mavuru, L., \& Ramnarain, U. (2020). Learners' socio-cultural backgrounds and science teaching and learning: A case study of township schools in South Africa. Cultural Studies of Science Education, 15(4), 1067-1095. https://doi.org/10.1007/s11422-020-09974-8

Meyer, X., \& Crawford, B. A. (2011). Teaching science as a cultural way of knowing: Merging authentic inquiry, nature of science, and multicultural strategies. Cultural Studies of Science Education, 6(3), 525-547. https://doi.org/10.1007/s11422-011-9318-6

Miller, P. M., Pavlakis, A., Samartino, L., \& Bourgeois, A. (2015). Brokering educational opportunity for homeless students and their families. International Journal of Qualitative Studies in Education, 28(6), 730-749. https://doi.org/10.1080/09518398.2015.1017860

Raia, F. (2018). Identity, tools and existential spaces. Learning, Culture and Social Interaction, 19, 74-95. https://doi.org/10.1016/j.lcsi.2018.04.014

Raia, F. (2020). The temporality of becoming: Care as an activity to support the being and becoming of the other. Mind, Culture, and Activity. https://doi.org/10.1080/10749039.2020.1745846

Raia, F., \& Deng, M. (2015). Relational medicine: Personalizing modern healthcare: The practice of high-tech medicine as a RelationalAct. London: Imperial College Press World Scientific.

Raia, F., Kwon, M., \& Deng, M. C. (2021). Teamwork, decision-making and high-tech healthcare: PERSON-SoulMindBodyHOOD \& Relational medicine. Imperial College Press/World Scientific.

Raia, F., \& Smith, M. S. (2020). Practitioners' noticing and know-how in multi-activity practice of patient care and teaching and learning. Cognition and Instruction, 38, 445-473. https://doi.org/10. 1080/07370008.2020.1782411

Robertson, M., Moir, J., Skelton, J., Dowell, J., \& Cowan, S. (2011). When the business of sharing treatment decisions is not the same as shared decision making: A discourse analysis of decision sharing in general practice. Health, 15(1), 78-95. https://doi.org/10.1177/1363459309360788

Roth, W.-M. (1997). The interaction of students' scientific and religious discourses: Two case studies. International Journal of Science Education, 19(2), 125-146. https://doi.org/10.1080/0950069970 190201

Roth, W.-M., \& Tobin, K. (2004). Cogenerative dialoguing and metaloguing: Reflexivity of processes and genres. In Forum qualitative sozialforschung/forum: Qualitative social research (Vol. 5, No. 3). http://www.qualitative-research.net/index.php/fqs/article/view/560

Roth, W.-M., Tobin, K., \& Ritchie, S. M. (2008). Time and temporality as mediators of science learning. Science Education, 92, 115-140. https://doi.org/10.1002/sce.20238

Sacks, H., Schegloff, E. A., \& Jefferson, G. (1974). A simplest systematics for the organization of turntaking for conversation. Language, 50, 696-735. https://doi.org/10.2307/412243

Schegloff, E. A. (1987). Analyzing single episodes of interaction: An exercise in conversation analysis. Social Psychology Quarterly, 50(2), 101-114. https://doi.org/10.2307/2786745 
Sharp, L. A. (1995). Organ transplantation as a transformative experience: Anthropological insights into the restructuring of the self. Medical Anthropology Quarterly, 9, 357-389. https://doi.org/10.1525/ maq.1995.9.3.02a00050

Sharp, L. A. (2006). Strange harvest: organ transplants, denatured bodies, and the transformed self. University of California Press.

Shildrick, M. (2012). Imagining the heart: Incorporations, intrusions and identity. Somatechnics, 2(2), 233-249. https://doi.org/10.3366/soma.2012.0059

Silverman, D., \& Peräkylä, A. (1990). AIDS counselling: The interactional organisation of talk about 'delicate' issues. Sociology of Health and Illness, 12, 293-318. https://doi.org/10.1111/1467-9566. ep11347251

Skelton, J. R., Wearn, A. M., \& Hobbs, F. D. R. (2002). "I" and "we": A concordancing analysis of how doctors and patients use first person pronouns in primary care consultations. Family Practice, 19, 484-488. https://doi.org/10.1093/fampra/19.5.484

Suárez-Orozco, C. (2004). Formulating identity in a globalized world. In M. Suarez-Orozco \& D. Qin-Hilliard (Eds.), Globalization: Culture and education in the new millennium (pp. 173-202). University of California Press.

Timmermans, S., \& Almeling, R. (2009). Objectification, standardization, and commodification in health care: A conceptual readjustment. Social Science \& Medicine, 69(1), 21-27. https://doi.org/10.1016/j. socscimed.2009.04.020

Vygotsky, L. S. (1978). Mind in society: The development of higher psychological processes. Cambridge: Harvard University Press.

Vygotsky, L. S. (2004). Imagination and creativity in childhood. Journal of Russian and East European Psychology, 42(1), 7-97. https://doi.org/10.1080/10610405.2004.11059210

Wirtz, V., Cribb, A., \& Barber, N. (2006). Patient-doctor decision-making about treatment within the consultation-A critical analysis of models. Social Science and Medicine, 62(1), 116-124. https://doi.org/ 10.1016/j.socscimed.2005.05.017

Publisher's Note Springer Nature remains neutral with regard to jurisdictional claims in published maps and institutional affiliations.

\section{Authors and Affiliations}

\section{Federica Raia ${ }^{1,2} \cdot$ Lezel Legados $^{1} \cdot$ Irina Silacheva ${ }^{2} \cdot$ Jennifer B. Plotkin ${ }^{2}$. Srikanth Krishnan ${ }^{1,2} \cdot$ Mario C. Deng ${ }^{2}$}

Lezel Legados

llegados@g.ucla.edu

Irina Silacheva

isilacheva@ucla.edu

Jennifer B. Plotkin

JPlotkin@mednet.ucla.edu

Srikanth Krishnan

SrikanthKrishnan@mednet.ucla.edu

Mario C. Deng

MDeng@mednet.ucla.edu

1 Department of Education, University of California, 405 Hilgard Avenue, Moore Hall 2335, Los Angeles, CA 90095-1521, USA

2 Department of Medicine, University of California, Los Angeles, USA 